\title{
Cotton Flea Beetle, Podagrica puncticollis Weise (Coleoptera: Halticidae) in Metema District, Northern Ethiopia: Yield Loss Assessment and Management
}

\author{
Eshetu Agegnehu Abebe \\ Department of Plant Sciences, Faculty of Agriculture, University of Gondar, Gondar, Ethiopia \\ Email: agegnehueshetu@yahoo.com
}

Received 12 November 2014; revised 18 December 2014; accepted 4 January 2015

Copyright (C) 2015 by author and OALib.

This work is licensed under the Creative Commons Attribution International License (CC BY). http://creativecommons.org/licenses/by/4.0/

(c) (i) Open Access

\section{Abstract}

Flea beetles are the most destructive insect pests of cotton in Northwestern part of Ethiopia. Damage is the most severe when seedlings are attacked and may necessitate extensive re-sowing. A field experiment was carried out in Metema districtfrom June to December in 2007 cropping season to estimate yield losses due to cotton flea beetle and to determine the efficacy of seed dressing and foliar insecticides against Podagrica puncticollis. The treatments were arranged by using RCBD with three replications. Seeds were treated with seed dressing insecticides (Cruiser 350 FS and Apron Star 42 WS) 5 days before sowing and foliar insecticide treatments (Sevin 85\% WP and Endosulfan 35\% EC) were applied 5 and 10 days after seedling emergence. No significant differences were observed among treatments in the number of flea beetles per plant before spraying with foliar insecticides. However, significant differences $(P<0.05)$ were observed among treatments in infestation of flea beetles before and after spray with foliar insecticides, indicated by the number of flea beetles after spray with foliar insecticides and the number of holes per damaged leaf. Plots sown with seeds treated with Cruiser, plots sown with seeds treated with Cruiser plus foliar spray with Sevin or Endosulfan 5 days after seedling emergence and 2 times spray of Sevin or Endosulfan 5 and 10 days after seedling emergence gave the least number of flea beetles per plant (1), infestation and showed less symptom of flea beetle damage with the least number of holes per damaged leaf (15) as compared to the other treatments which gave similar results to untreated check ( 22 flea beetles and 55.2 holes). Significant differences $(P<0.05)$ were observed among treatments in some agronomic characteristics of cotton. Plots sown with seeds dressed with Cruiser combined with foliar spray with Sevin or Endosulfan 5 days after seedling emergence showed significant differences and gave more number of leaves per plant (81), maximum plant height $(95.2 \mathrm{~cm})$, no reduction of plant stand per plot and more seed cotton yield $(0.49 \mathrm{~kg})$ of all the other treatments, whereas, seeds dressed with Apron Star solely and seeds dressed with Apron Star plus foliar spray with Sevin or Endosulfan 5 days after seedling emergence gave the least results and no differences were observed as compared to untreated check in some agro- 
nomic features of cotton ( 38 leaves, $58.1 \mathrm{~cm}$ and $0.1 \mathrm{~kg}$ ). A seed cotton yield loss of $75.51 \%$ was recorded in untreated plots as compared to seeds treated with Cruiser plus foliar spray with Sevin 5 days after seedling emergence. Using Cruiser as a sole seed dressing insecticide and supplementing those seeds treated with Cruiser by foliar spraying with Sevin 5 days after seedling emergence provided the most reasonable management approach for cotton flea beetle.

\title{
Keywords
}

\author{
Cotton Flea Beetle, Yield Loss, Management
}

Subject Areas: Agricultural Science, Plant Science

\section{Introduction}

Cotton (Gossypium hirsutum L.) is an important cash crop for both small and large scale farmers in Ethiopia. Cotton is a source of raw material for textile industries and oil extracting mills. Of the global 33.5 million hectares of cotton worth $\$ 20$ billion, approximately $70 \%$ is grown in developing countries; Fifty percent of world cotton is grown in Asia, up to 15\% in Africa and less than 5\% in Latin America [1]. The actual and potential cottons growing areas in Ethiopia are located around the central highlands [2].

Cotton production and productivity is often constrained by both biotic and abiotic stresses [3]. No less than 1326 species of insects have been recorded on this crop, 482 from Africa, South of the Sahara [4]. In Ethiopia, a pest complex of 68 species of insects and mite has been reported [5]. Of these, the major pests are cotton bollworm (Helicoverpa armigera Hübner), Sudan bollworm (Diparopsis watersi Roths), spiny bollworm (Earias insulana Boisd.), pink bollworm (Pectinophora gossypiella Saunders), cotton aphid (Aphis gossypii Glover), whitefly (Bemisia tabaci Genn.), stainers (Dysdercus spp.), green leafhopper (Empoasca lybica de Berg.), flea beetle (Podagrica puncticollis Weise), cotton leaf worm (Spodoptera littoralis Boisd.) and red mites (Tetranychus spp.). Cotton flea beetle, $P$. puncticollis, is the main species recorded on cotton in Ethiopia and neighboring countries and it has proven to be a major pest occasionally causing extensive losses [6].

A recent study revealed that $P$. podagrica was considered the second most important pest of cotton after bollworm [7]. The amount of defoliation should be used as a guide to determine the need for management action [8]. Seed dressing is also recommended as a routine practice [4]. Infestation of cotton by $P$. puncticollis has recently increased in the North Western Amhara region, especially in North Gondar, Metema district. All cotton fields in the area are severely affected and sometimes completely wiped out by the flea beetle and farmers are forced to substitute cotton by sesame and sorghum. $P$. puncticollis is now recognized as one of the major destructive pests of cotton in Metema. Hence, it is one of the top priority pests in the Amhara Regional state. However, no empirical information exists on cotton flea beetle with regard to its distribution and damage. Such information is important to design effective management strategies against the pest. This study was proposed to estimate yield losses due to $P$. puncticollis and to determine the efficacy of seed dressing and foliar insecticides against this important pest.

\section{Materials and Methods}

\subsection{Description of the Experiment Site}

The field experiment was carried out in Kumer-Aftete locality in Metema district of the Amhara Regional State. It is located about $900 \mathrm{~km}$ North West of Addis Ababa and about $180 \mathrm{~km}$ West of Gondar town. The district has an international boundary of more than $60 \mathrm{~km}$ between Ethiopia and Sudan. The altitude of Metema ranges from 550 to 1608 meters above sea level. The minimum and maximum annual temperatures range between $22^{\circ} \mathrm{C}$ and $28^{\circ} \mathrm{C}$ respectively. The daily average temperature is high during the months of March to May reaching as high as $43^{\circ} \mathrm{C}$. The rainy months extend from June to September. However, much rainfall is received during the months of July and August and the mean annual rainfall of the area ranges from about 850 to $1100 \mathrm{~mm}$. Metema has unimodal rainfall [9]. 


\subsection{Experimental Materials and Design}

\subsubsection{Cotton Planting}

The treatments were arranged in randomized complete block design with three replications. The plot size was 5 $\mathrm{m} \times 4 \mathrm{~m}$ and there were five rows of cotton plants per plot. Each row was $5 \mathrm{~m}$ long. The spacing between plants and between rows was 25 and $80 \mathrm{~cm}$, respectively. To avoid wind drift, plots were spaced $2 \mathrm{~m}$ apart. The spacing between blocks was $1.5 \mathrm{~m}$.

\subsubsection{Insecticides}

Four insecticides were used in this study: Cruiser ( $0.112 \mathrm{ml}$ per plot), Apron Star (0.08 gram per plot), Sevin (0.003 kg per plot) and Endosulfan (0.004 liter per plot). Detailed descriptions of insecticides are indicated in Appendix. The cotton variety used was Akala SJ2. The seeds of the variety were divided into four groups. The first and second groups were treated with Cruiser and Apron Star, respectively. The third and fourth groups of seeds were used for foliar applied insecticides, Sevin and Endosulfan, respectively. In seed dressing insecticides, seeds were treated five days before planting, while in foliar applied insecticides, plants were sprayed with the respective insecticides 5 and 10 days after seedling emergence using knapsack sprayer. An untreated check was maintained for comparison purposes. Weeding was done by hand. Treatment details are given below in (Table 1).

\subsubsection{Data Collection}

Infestation level of flea beetles, damage and number of flea beetles per plant were recorded before and after spraying of the foliar insecticides. Level of infestation of cotton flea beetle was determined by considering the proportion of plants in a sample which were colonized by the flea beetles or which showed damage symptoms. Damage was recorded as number of holes per damaged leaf, and the number of leaves per plant and plant height were also recorded from ten arbitrarily selected plants in the central three rows per plot. Number of flea beetles before and after spray with foliar insecticides was recorded from sampled plants from each plot (the pre-spraying counts were made 24 hours before spraying and post-spraying counts were made 24 hours after application). Counting of the flea beetle was done by shaking of individual plant on to a $40 \mathrm{~cm} \times 40 \mathrm{~cm}$ box.

Table 1. Treatment details of field experiment.

\begin{tabular}{|c|c|}
\hline Treatments & Designation/code \\
\hline Seeds dressed with Cruiser & Cruiser seed \\
\hline Seed dressed with Apron Star & Apron Star seed \\
\hline Sevin sprayed 5 days after seedling emergence & Carbaryl 5 days \\
\hline Sevin sprayed 10 days after seedling emergence & Carbaryl 10 days \\
\hline Sevin sprayed 5 and 10 days after seedling emergence & Carbaryl 5 and 10 days \\
\hline Endosulfan sprayed 5 days after seedling emergence & Endosulfan 5 days \\
\hline Endosulfan sprayed 10 days after seedling emergence & Endosulfan 10 days \\
\hline Endosulfan sprayed 5 and 10 days after seedling emergence & Endosulfan 5 and 10 days \\
\hline $\begin{array}{l}\text { Sevin sprayed } 5 \text { days after seedling emergence on } \\
\text { plots sown with seeds dressed with Cruiser }\end{array}$ & Cruiser seed + Carbaryl 5 days \\
\hline $\begin{array}{l}\text { Endosulfan sprayed } 5 \text { days after seedling emergence on } \\
\text { plots sown with seeds dressed with Cruiser }\end{array}$ & Cruiser seed + Endosulfan 5 days \\
\hline $\begin{array}{l}\text { Sevin sprayed } 5 \text { days after seedling emergence on } \\
\text { plots sown with seeds dressed with Apron Star }\end{array}$ & Apron Star seed + Carbaryl 5 days \\
\hline $\begin{array}{l}\text { Endosulfan sprayed } 5 \text { days after seedling emergence on } \\
\text { plots sown with seeds dressed with Apron Star }\end{array}$ & Apron Star seed + Endosulfan 5 days \\
\hline Untreated check (sprayed with water only) & Untreated \\
\hline
\end{tabular}


Additionally, the extent of leaf damage one month after application of insecticides was estimated by counting the number of holes from five damaged leaves from each sampled plant. Number of intact leaves present per plant was counted during the appearance of first flower bud squares. Plant height was measured in centimeters by using a ruler at harvest from the bottom up to the tip of the plant Stand count at emergence and at harvest was taken by counting the number of plants in each plot. Percent reduction in plant stand was calculated based on results from stand counted at emergence and harvest. Cotton harvesting was made by hand and pickings were made two times. Cotton yield was calculated based on ten plants per plot especially from the central three rows of each plot.

Yield Loss Assessment: Damage assessment or the percentage yield loss due to cotton flea beetle was calculated for each treatment using the formula suggested by Judenko [10] and Walker [11] as the difference between insecticides treated and untreated plots.

$$
\text { Yield loss }(\%)=\frac{(\bar{x}-\bar{y})}{\bar{x}} \times 100
$$

where, $\bar{x}=$ mean seed cotton yield of treated plots; $\bar{y}=$ mean seed cotton yield of untreated plots.

\subsubsection{Data Analysis}

Data on number of flea beetles per plant before and after spray of foliar insecticides were subjected to square root transformation whereas arcsine (angular) transformation was used for data on infestation of cotton flea beetles before and after spray with foliar insecticides. The analysis of variance (ANOVA) was carried out by using SAS statistical computer software package V.8.3 [12] and means were separated and compared by using Least Significance Difference (LSD) tested at alpha 0.05 probability level [13].

\section{Results and Discussions}

\subsection{Evaluation of Some Insecticides against Flea Beetle in Cotton}

\subsubsection{Infestation of Flea Beetle before Spray with Foliar Insecticides}

There were significant differences $(\mathrm{P}<0.05)$ between treatments of seed dressing insecticides (sole) in infestation of flea beetles before spray with foliar insecticides (Table 2). There were no significant differences among treatments sown with seeds treated with Apron Star and those treatments with foliar applications of Sevin and Endosulfan at both times of application. The highest infestation of flea beetles (60\% to 76.67\%) was observed from the above mentioned treatments. However, the least infestation of flea beetle (23.3\% to $36.6 \%$ ) was observed from plots sown with seeds dressed with Cruiser. The infestation of flea beetle observed from the remaining treatments ranged from $40 \%$ to $76.3 \%$. Thomas et al. [14] reported that Thiamethoxam seed treatment reduced flea beetle feeding injury to leaves of corn and reduced insect infestation ranging $37 \%$ to $83 \%$ which is in accordance with the present study.

\subsubsection{Infestation of Flea Beetle after Spray with Foliar Insecticides}

There were significant differences $(\mathrm{P}<0.05)$ among treatments in infestation of flea beetle after spray with foliar insecticides (Table 2). However, there were no significant differences between seed dressed with Apron Star and seed dressed with Apron Star in combination with foliar spray with Sevin or Endosulfan 5 days after seedling emergence. In these treatments, the infestation of cotton flea beetle ranged from $66.6 \%$ to $71.6 \%$. However, the least infestation level (10\% to 13.3\%) of cotton flea beetle was observed from seed treated with Cruiser and combined with foliar spray with Sevin or Endosulfan 5 days after seedling emergence. Thomas et al. [14] reported that Cruiser seed treatment reduced flea beetle feeding injury to leaves of corn and reduced insect infestation ranging $37 \%$ to $83 \%$ which is in accordance with the present study. Similarly, Webster [15] reported that cotton seed treatment with organo-chlorine successfully controlled cotton flea beetle, thrips, aphids and spider mites for 4 to 6 weeks after plant emergence.

Two times foliar spray with Sevin or Endosulfan 5 and 10 days after seedling emergence showed infestation of $20 \%$ and $23 \%$ respectively, comparatively better to seeds treated with Cruiser. The infestation of cotton flea beetle observed from the remaining treatments ranged from $33.3 \%$ to $63.3 \%$. Earlier and recent finds were in accordance with the present investigations such as, Schmutterer [16] reported that seed dressing with Dieldrin at a rate of about $4 \mathrm{~g}$ a.i. per kilogram of cotton seed results in an obvious reduction of cotton flea beetle infestation 
Table 2. Infestation level of cotton flea beetle in different treatments at Metema in 2007.

\begin{tabular}{|c|c|c|c|c|c|}
\hline Treatments & $\begin{array}{c}\text { Number of flea } \\
\text { beetles } 24 \text { hrs } \\
\text { before spray }\end{array}$ & $\begin{array}{c}\text { Number of flea } \\
\text { beetles } 24 \text { hrs } \\
\text { after spray }\end{array}$ & $\begin{array}{l}\text { Infestation of flea } \\
\text { beetles before } \\
\text { spray (\%) }\end{array}$ & $\begin{array}{c}\text { Infestation of flea } \\
\text { beetles after } \\
\text { spray (\%) }\end{array}$ & $\begin{array}{l}\text { Number of holes } \\
\text { per damaged leaf }\end{array}$ \\
\hline Cruiser seed & $5(2) \pm 0.3$ & $3(1) \pm 0.7$ efg & 36.6(37.1) \pm 3.9cde & $20(25.3) \pm 6.9$ de & $23.6 \pm 1.8 \mathrm{fg}$ \\
\hline Apron Star seed & $10(3) \pm 0.7$ & $15(4) \pm 0.0 \mathrm{ab}$ & $76.67(61.2) \pm 2.2 \mathrm{a}$ & $71.6(57.9) \pm 1.1 \mathrm{a}$ & $46.2 \pm 4.6 b$ \\
\hline Sevin 5 days & $9(3) \pm 3.5$ & $5(2) \pm 0.7 \mathrm{cdef}$ & $63.33(53) \pm 5.4 a b$ & $43.3(41.1) \pm 1.9 b c$ & $31 \pm 2.8$ de \\
\hline Sevin 10 days & $14(4) \pm 0.6$ & $4(2) \pm 0.3 a b c d$ & $76.67(62.7) \pm 8.86 a$ & $43.3(41.1) \pm 3.9 b c$ & $29.3 \pm 3.0 \mathrm{ef}$ \\
\hline Sevin and 10 days & $11(3) \pm 0.3$ & $3(1) \pm 0.7$ efg & $60(51.1) \pm 6.1 \mathrm{abc}$ & $23.3(28.8) \pm 2.2 \mathrm{ce}$ & $25.1 \pm 1.0 \mathrm{efg}$ \\
\hline Endosulfan 5 days & $10(3) \pm 0.3$ & $9(3) \pm 0.3 a b c$ & $76.76(61.2) \pm 2.2 \mathrm{a}$ & $63.3(52.8) \pm 2.0 \mathrm{ab}$ & $38.9 \pm 1.4 \mathrm{c}$ \\
\hline Endosulfan 10 days & $5(2) \pm 0.7$ & $4(2) \pm 0.0$ abcde & $40(38.8) \pm 6.9$ cde & $33.3(35.0) \pm 4.2 \mathrm{~cd}$ & $36.7 \mathrm{~cd} \pm 1.0$ \\
\hline Endosulfan 5 and 10 days & $7(2) \pm 0.3$ & $2(1) \pm 1$ efg & $53.3(46.9) \pm 3.8 b c d$ & $20(25.2) \pm 8.0 \mathrm{de}$ & $28.8 \pm 2.8 \mathrm{ef}$ \\
\hline Cruiser + Carbaryl 5 days & $4(2) \pm 0.6$ & $1(0) \pm 0 g$ & $23.3(28.8) \pm 2.2 \mathrm{e}$ & $10(18.4) \pm 0.0 \mathrm{e}$ & $15 \pm 1.8 \mathrm{~h}$ \\
\hline Cruiser + Endosulfan 5 days & $5(2) \pm 0.3$ & $1(0) \pm 0 g$ & $36.6(36.9) \pm 5.4 \mathrm{de}$ & $13.3(20.8) \pm 5.8 \mathrm{e}$ & $21 \pm 1.4 \mathrm{hg}$ \\
\hline Apron Star + Sevin 5 days & $11(3) \pm 0.3$ & $10(3) \pm 0.9 a b$ & $63.3(53.1) \pm 7.2 \mathrm{ab}$ & $66.6(55.0) \pm 4.2 \mathrm{a}$ & $43.1 \pm 2.8 b c$ \\
\hline Apron Star + Endosulfan 5 days & $12(3) \pm 0.3$ & $11(3) \pm 1.2 \mathrm{ab}$ & $60(50.8) \pm 3.4$ abcd & $70(57.0) \pm 0.6 a$ & $46.2 \pm 3.7 b$ \\
\hline Untreated & $20(5) \pm 0.3$ & $22(5) \pm 0.0 a$ & $53.3(46.9) \pm 9 b c d$ & $75(60.1) \pm 1.9 a$ & $55.2 \pm 0.9 \mathrm{a}$ \\
\hline LSD & ns & 4.2 & 22.5 & 17.7 & 6.5 \\
\hline CV (\%) & 39 & 35 & 2.4 & 24 & 11 \\
\hline
\end{tabular}

Note: Means with the same letter are not significantly different; Values under parenthesis indicated transformed values and ns = non-significant.

and damage to seedlings and Porter [17] reported that Thiamethoxam, the active ingredient in Cruiser, moves systemically throughout the plant and protects against target pests through contact and stomach activity. Once absorbed through contact or feeding, Cruiser interferes with the receptors in an insect that transmit the message to feed. As a result, the insect stops feeding and the plants are protected. Rick et al. [18] indicated that most flea beetle adults are easily controlled with foliar dusts or sprays or with systemic insecticides applied at planting time. The present investigation shows similar trends to those reported by previous workers.

\subsubsection{Number of Holes per Damaged Leaf}

There were significant differences $(\mathrm{P}<0.05)$ among treatments in number of holes per damaged leaf (Table 2). Seed treated with Apron Star and seed treated with Apron Star plus foliar spray with Sevin or Endosulfan resulted in the highest range of holes per damaged leaf (43 to 46) next to the untreated check (55 holes per leaf). However, spray with Carbaryl or Endosulfan on plots sown with seeds treated with Cruiser 5 days after seedling emergence caused the least number (15 to 21 ) of holes per damaged leaf followed by two times foliar spray with Sevin or Endosulfan 5 and 10 days after seedling emergence. The number of holes per damaged leaf recorded from the remaining treatments ranged from 29.3 to 38.9. The above findings were supported by Badawi [19] who reported that treatment with Carbaryl resulted in $7.5 \%$ of the leaf damaged with 11.2 mean numbers of holes per leaf. Similarly, James [20] reported that for conventional growers, pesticides containing pyrethroids or carbamates (Sevin) are generally effective.

\subsubsection{Number of Flea Beetles per Plant before Spray with Foliar Insecticides}

There were no significant differences $(\mathrm{P}>0.05)$ between treatments in number of flea beetles per plant before spraying with foliar insecticides (Table 2). However, treatments of seeds treated with Apron Star resulted in the highest number (10 to 12) of flea beetles next to untreated check (20 flea beetles per plant). The least number (4 to 5) of flea beetles was recorded from treatments of seeds with Cruiser. 


\subsubsection{Number of Flea Beetle per Plant after Spray with Foliar Insecticides}

There were significant differences $(\mathrm{P}<0.05)$ between treatments in number of flea beetles per plant after foliar applications (Table 2). The highest number (15 flea beetles per plant) of flea beetles was recorded from seed dressed with Apron Star followed by seed dressed with Apron Star combined with foliar spray with Sevin or Endosulfan 5 days after seedling emergence with 10 to 11 flea beetles per plant which were next to untreated check (22 flea beetles per plant). However, the least number of flea beetles was recorded from seed treated with Cruiser plus foliar spray with Sevin or Endosulfan 5 days after seedling emergence ( 1 flea beetle per plant). Medium level of population was observed from seeds dressed with Cruiser, two times foliar spray with Sevin or Endosulfan 5 and 10 days after seedling emergence and foliar application of Sevin 5 days after seedling emergence. Foliar spray with Endosulfan 5 days after seedling emergence showed highest number of flea beetles (9) next to seeds treated with Apron Star.

\subsection{Effect of Insecticides Applied against Cotton Flea Beetle on Some Agronomic Characteristics and Yield of Cotton}

\subsubsection{Plant Height at Harvest}

There were significant differences $(\mathrm{P}<0.05)$ among treatments in affecting plant height (Table 3). Spray with either Sevin or Endosulfan 5 days after seedling emergence on in plots sown with seeds treated with Cruiser produced the tallest plants $(91.2$ to $95.2 \mathrm{~cm})$ followed by seeds treated with Cruiser $(86.9 \mathrm{~cm})$. Medium plant height $(81.4$ to $83 \mathrm{~cm}$ ) was measured from two times spray with Sevin or Endosulfan 5 and 10 days after seedling emergence. However, spray with Sevin or Endosulfan 5 days after seedling emergence on plots sown with seeds treated with Apron Star and seeds treated with Apron Star solely produced the shortest plants (65.6 to 70.6 $\mathrm{cm}$ ). Plant heights recorded from the remaining insecticide treatments ranged from 71.8 to $80.4 \mathrm{~cm}$. Jude [21] reported that Cruiser seed treatment maximizes the growth potential of the crop by enabling early season vigor includes greater density, plant height, root length, stem diameter, number of leaves per plant and high yield. The

Table 3. Effect of insecticides applied against flea beetle on some agronomic characteristics of cotton plants at Metema in 2007.

\begin{tabular}{cccc}
\hline Treatments & $\begin{array}{c}\text { Plant height } \\
\text { at harvest }(\mathrm{cm})\end{array}$ & $\begin{array}{c}\text { Number of leaves at } \\
\text { the appearance of first } \\
\text { flower bud squares }\end{array}$ & $\begin{array}{c}\text { Percent reduction } \\
\text { in plant stand }\end{array}$ \\
\hline Cruiser seed & $86.9 \pm 0.2 \mathrm{bc}$ & $80 \pm 0.6 \mathrm{a}$ & 3.20 \\
Apron Star seed & $65.6 \pm 4.6 \mathrm{~h}$ & $43 \pm 8.5 \mathrm{c}$ & 11.24 \\
Sevin 5 days & $78 \pm 0.4 \mathrm{de}$ & $77 \pm 1.3 \mathrm{a}$ & 5.13 \\
Sevin 10 days & $80.4 \pm 0.4 \mathrm{~d}$ & $79 \pm 2.7 \mathrm{a}$ & 2.86 \\
Sevin 5 and 10 days & $83 \pm 0.5 \mathrm{~cd}$ & $77 \pm 4.3 \mathrm{a}$ & 1.29 \\
Endosulfan 5 days & $71.8 \pm 1.5 \mathrm{fg}$ & $66 \pm 6.7 \mathrm{ab}$ & 8.00 \\
Endosulfan 10 days & $73.7 \pm 1.6 \mathrm{ef}$ & $65 \pm 12.7 \mathrm{ab}$ & 5.43 \\
Endosulfan 5 and 10 days & $81.4 \pm 0.1 \mathrm{~d}$ & $79 \pm 2.7 \mathrm{a}$ & 3.09 \\
Cruiser + Sevin 5 days & $95.2 \pm 1.2 \mathrm{a}$ & $81 \pm 1.7 \mathrm{a}$ & 0.00 \\
Cruiser + Endosulfan 5 days & $91.2 \pm 0.7 \mathrm{ab}$ & $80 \pm 2.9 \mathrm{a}$ & 0.00 \\
Apron Star + Sevin 5 days & $70.6 \pm 0.8 \mathrm{fg}$ & $54 \pm 10.7 \mathrm{bc}$ & 10.29 \\
Apron Star + Endosulfan 5 days & $68.6 \pm 2.7 \mathrm{gh}$ & $47 \pm 9.5 \mathrm{bc}$ & 8.79 \\
Untreated & $58.1 \pm 1.4 \mathrm{i}$ & $38 \pm 5.3 \mathrm{c}$ & 40.00 \\
LSD & 5 & 19.4 & 17 \\
CV (\%) & 3.8 & 5 & \\
\hline
\end{tabular}

Note: Means with the same letter are not significantly different and Percent reduction in plant stand was computed by using data from stand counted at emergence and harvest. 
findings of this present study with reference to plant height are in agreement with findings of Jude [21].

\subsubsection{Number of Leaves per Plant at Harvest}

There were significant differences $(\mathrm{P}<0.05)$ among treatments in number of leaves per plant (Table 3$)$. There were no significant differences among seed treated with Cruiser, foliar applied insecticides (Sevin and Endosulfan) and combination of seed treated with Cruiser and foliar applied insecticides in affecting number of leaves per plant. However, the highest number of leaves per plant (80 to 81) was recorded from plots sown with seeds treated with Cruiser and seeds treated with Cruiser plus foliar spray with Sevin or Endosulfan 5 days after seedling emergence. Medium number of leaves (77 to 79) from foliar applied insecticides except foliar spray with Endosulfan 5 or 10 days after seedling emergence showed 65 to 66 numbers of leaves next to the medium ones. However, seed treated with Apron Star only and seed treated with Apron Star combined with foliar spray with Sevin or Endosulfan resulted in the least number of leaves per plant (43 to 54) next to the untreated check (38).

\subsubsection{Percent Reduction in Plant Stand}

There were differences among treatments in percent reduction of plant stand per plot due to cotton flea beetle infestation (Table 3). There were no differences between plots sown with seeds treated with Cruiser, plots spray with Sevin 10 days after seedling emergence and plots spray with Endosulfan 5 and 10 days after seedling emergence. Porter [17] reported that sunflower seed treated with Cruiser against sunflower beetle showed about $15 \%$ increase stand establishment and an average of about 2500 to 3000 additional plants per acre. The present result is also in line with Jude [21]. These authors reported that sunflower seed treated with Cruiser against wireworm, sunflower beetle and flea beetle can help improve plant stand and vigor.

The highest percent reduction of plant stand per plot was observed on plots sown with seeds treated with Apron Star (11.24) and plots sown with seeds treated with Apron Star plus foliar application of Sevin or Endosulfan 5 days after seedling emergence (8.79 to 10.29) next to the untreated check (40). The least percent reduction of plant stand per plot (0 to 1.29) was observed from plots sown with seeds treated with Cruiser plus foliar application of Sevin or Endosulfan 5 days after seedling emergence and foliar applications of Sevin 5 and 10 days after seedling emergence. The percent reduction of plant stand per plot observed from the remaining treatments ranged from 5.13 to 8 . Osman et al. [22], proved that an average of one spray or less per season was effective to control cotton jassids and to some extent whiteflies and flea beetles, $P$. puncticollis.

\subsubsection{Yield and Yield Loss}

There were significant differences $(\mathrm{P}<0.05)$ among treatments in seed cotton yield (Table 4). The highest yields of seed cotton from ten plants per plot ( 0.47 to $0.49 \mathrm{~kg}$ ) was obtained from plots sown with seeds dressed with Cruiser plus foliar spray with Sevin or Endosulfan 5 days after seedling emergence. This was followed by seed treated with Cruiser solely $(0.42 \mathrm{~kg})$. There were, however, no significant differences among foliar spray of Sevin or Endosulfan 5 and 10 days after seedling emergence and foliar spray of Sevin 10 days after seedling emergence.

Plots sown with seeds treated with Apron Star in all cases resulted in the lowest seed cotton yield from ten plants per plot ( 0.20 to $0.26 \mathrm{~kg}$ per ten plants). Seed cotton yield of ten plants per plot from the remaining treatments ranged from 0.27 to $0.35 \mathrm{~kg}$. Anthony and Mike [23] indicated that with proper insect pest management, yields of seed cotton could be increased from 224 to $448 \mathrm{~kg}$ per hectare to 1680 to $2240 \mathrm{~kg}$ per hectare. Cruiser seed treatment maximizes the growth potential of the crop by enabling early season vigor, a visible increase in bloom, fruit development and a higher yield [21]. Lloyd and Ripper [24] indicated that the chemical control with sprays of Endrin and seed dressing of Dieldrin applied at a rate of $8.5 \mathrm{~kg}$ per 0.42 hectare resulted in control of the flea beetle and termites. The resulted was obtained as a result of translocation of the chemicals through the plant, making the leaves toxic to the pests. An improved yield of $107 \mathrm{~kg}$ per 0.42 hectare was obtained.

Metcalf [25] indicated that sunflower seed treated with Cruiser can help improve plant stand and ultimately increase yield. A seed cotton yield loss of $75.51 \%$ was recorded in untreated plots as compared to seeds treated with Cruiser plus foliar spray with Sevin 5 days after seedling emergence (Table 3).

Throne [8] reported that yield losses of about $10 \%$ are common where flea beetles are abundant, even when the crop is protected with insecticides and a one per cent yield reduction per acre results in a total crop loss of about \$25 to \$35 million. Schmutterer [2] also indicated that Podagrica spp. are serious pests of short staple cotton reducing the yield in the Nubia mountains (Sudan) to the low average of about $499 \mathrm{~kg}$ of seed cotton per 
Table 4. Yield and yield loss due to cotton flea beetle in different treatments at Metema in 2007.

\begin{tabular}{cccc}
\hline & Seed cotton yield & \multicolumn{2}{c}{ Seed cotton yield } \\
\cline { 3 - 4 } Trom ten plants & per plot (kg) & $\begin{array}{c}\text { Yield loss if not } \\
\text { treated }(\mathrm{kg})\end{array}$ & $\begin{array}{c}\text { Yield loss if not } \\
\text { treated (\%) }\end{array}$ \\
Cruiser seed & $0.42 \pm 1.94 \mathrm{~b}$ & 0.30 & 71.42 \\
Apron Star seed & $0.20 \pm 4.64 \mathrm{~h}$ & 0.08 & 40.00 \\
Sevin 5 days & $0.29 \pm 1.01 \mathrm{def}$ & 0.17 & 58.62 \\
Sevin 10 days & $0.31 \pm 2.89 \mathrm{cde}$ & 0.19 & 61.29 \\
Sevin 5 and 10 days & $0.35 \pm 0.356 \mathrm{c}$ & 0.23 & 65.71 \\
Endosulfan 5 days & $0.27 \pm 0.34 \mathrm{ef}$ & 0.15 & 55.55 \\
Endosulfan 10 days & $0.29 \pm 0.38 \mathrm{ef}$ & 0.17 & 64.62 \\
Endosulfan 5 and 10 days & $0.34 \pm 1.13 \mathrm{~cd}$ & 0.22 & 75.51 \\
Cruiser + Sevin 5 days & $0.49 \pm 1.83 \mathrm{a}$ & 0.37 & 74.46 \\
Cruiser + Endosulfan 5 days & $0.47 \pm 1.30 \mathrm{ab}$ & 0.35 & 53.84 \\
Apron Star + Sevin 5 days & $0.26 \pm 0.23 \mathrm{fg}$ & 0.14 & 45.45 \\
Apron Star + Endosulfan 5 days & $0.22 \pm 1.07 \mathrm{gh}$ & 0.10 & \\
Untreated & $0.12 \pm 1.66 \mathrm{i}$ & & \\
LSD & 0.0049 & & \\
CV (\%) & 9.34 & & \\
\hline
\end{tabular}

Note: Means with the same letter are not significantly different and yield loss is computed as the difference between treated and untreated plots.

0.42 hectare and in various experiments it was shown that the effective control of this pest may result in a yield as high as 2384 per 0.42 hectare. The above reports were in concurrence with the present investigation.

\section{Conclusion}

The field experiment in Metema district was conducted to determine yield loss and to evaluate the efficacy of seed dressing and foliar insecticides against $P$. puncticollis. A seed cotton yield loss of $75.51 \%$ was recorded in untreated plots as compared to seeds treated with Cruiser plus foliar spray with Carbaryl 5 days after seedling emergence. Flea beetles attacking cotton in Metema were successfully controlled by using seeds treated with Cruiser combined with foliar spray with Carbaryl or Endosulfan 5 days after seedling emergence and using only seeds treated with Cruiser. Two times foliar spray with Carbaryl or Endosulfan at 5 and 10 days after seedling emergence also gave promising results for those seedlings which were not grown with a seed treatment. Further studies on integrated cotton flea beetle management using resistant or tolerant varieties, planting dates, crop rotation and field sanitation in conjunction with appropriate selective insecticides should be carried out. Additional studies should be conducted on the biology and ecology of cotton flea beetle.

\section{Acknowledgements}

This study (M.Sc. Thesis) was conducted with the financial support from Amhara Regional Agricultural Research Institute, Ethiopia, 2007.

\section{References}

[1] Clive, J. (2001) Global Review of Commercial Transgenic Crops: Crops Generaglobal Economics. Environmental and Social Benefits, 17, 1-5. 
[2] Girma, B. (1982) Cotton Yield Trials at the Various Agro-Climatic Zones and Summary of Cotton National Variety Trials. Proceedings of Symposium on Cotton National Variety Trials, IAR, Melkawere, 35-48.

[3] EARO (Ethiopian Agricultural Research Organization) (2000) Cotton Research Strategy. Research Directorate. Addis Ababa, 32 p. Gomez, K.A. and Gomez, A.A. (1984) Statistically Procedures for Agricultural Research. 2nd Edition, John Wiley and Sons Inc., Hoboken, 680 p.

[4] Mohamed, M. and Mohamed, A. (2000) Studies on the Control of Insect Pests in Vegetables (Okra, Tomato, and Onion) in the Sudan with Special Reference to Neem Preparations. M.Sc. Thesis, University of Giessen, Giessen.

[5] Abate, T. (1982) Cotton Pest Problems and Their Control in Ethiopia. Proceedings of Symposium on Cotton Production under Irrigation, IAR, Melkawerer, 111-123.

[6] IAR (Institute of Agricultural Research) (1972) Progress Report for the Period April 1971 to March 1972. Addis Ababa, $75 \mathrm{p}$.

[7] Yalew, T. (2005) Species Composition of Cotton Bollworms (Lepidoptera: Noctuidae and Gelechiidae) and Their Management Using Cotton Genotypes and Planting Dates in Metema, Northern Ethiopia. M.Sc. Thesis, Alemaya University.

[8] Throne, S. (2007) Flea Beetle Management for Canola, Rapeseed, and Mustard in the Northern Great Plains. Saskatchewan Agriculture Green Plan Agreement, Canada, 45 p.

[9] IPMS (Improving Productivity and Market Success) (2005) Metema Learning Site Diagnosis and Program Design (Unpublished). ILRI (International Livestock Research Institute), Ethiopia.

[10] Judenko, E. (1973) Analytical Methods for Assessing Yield Losses Caused by Pests on Cereal Crops with and without Pesticide. Tropical Bulletin No. 2. Center for Overseas Pest Research, UK, 31 p.

[11] Walker, P.T. (1987) The Assessment of Crop Losses in Cereals. Insect Science and Its Application, 4, 97-104.

[12] SAS Institute (1996) SAS User’s Guide: Statistics. V. 8.3 Edition, SAS Institute, Cary.

[13] Gomez, K.A. and Gomez, A.A. (1984) Statistical Procedures for Agricultural Research. 2nd Edition, John Wiley and sons Inc., Hoboken, 680 p.

[14] Kuhar, T.P., Stivers-Young, L.J., Hoffmann, M.P. and Taylor, A.G. (2002) Management of Flea Beetle by Using Seed Dressing Insecticides. Cornell University, Ithaca, $32 \mathrm{p}$.

[15] Webster (1982) Pest Management Guidelines of Cole Crops. UC IPM, University of California, Davis, 7-8.

[16] Schmutterer, H. (1969) Pests of Crops in Northeast and Central Africa with Particular Reference to the Sudan. Gustav Fischer Verlag, Stuttgart and Portland, 136-138.

[17] Keith, P. (2007) Evaluation of Surround for Pest Control on Eggplant. Plant \& Pest Advisory. Rutgers Cooperative Extension, University of New Jersey, Brunswick, 1-2.

[18] Foster, R.E. and Obermeyer, J.L. (2004) Flea Beetle Control in Vegetable Crops. Purdue University, West Lafayette, $340 \mathrm{p}$.

[19] Badawi, A. (1971) Chemical Control of the Cotton Flea Beetle Podagrica puncticollis Weise in the Sudan (Halticidae, Coleoptera). Zeitschrift für Angewandte Entomologie, 68, 79-82.

[20] James, L. (1999) Insect Pests of Leafy Vegetables, Cole Crops and Melons in Arizona. Cambridge University Press, Cambridge, $23 \mathrm{p}$

[21] Jude, B. (2006) New England Vegetable Management Guide. University of Connecticut Cooperative Extension System, $390 \mathrm{p}$.

[22] Osman, G.H., Jone, D. and Balla, A.N. (1985) Pesticide Use in the Sudan Gezira: Past, Present and Future. Pesticide Management in East and Southern Africa. Proceedings of a Regional Workshop, Nairobi, 10-15 March 1985, 39.

[23] Youdeowei, A. and Service, M.W. (1986) Pest and Vector Management in the Tropics. English Language Book Society, London, $380 \mathrm{p}$.

[24] Lloyd, G. and Ripper, W.E. (1965) Cotton Pests of the Sudan: Their Habits and Control. Backwell Scientific Publications, Oxford, 150-153.

[25] Metcalf, R.L. (2007) Vegetable Management Guide. University of Okhlama Cooperative Extension System, 39 p. 


\section{Appendix}

Lists of insecticides used in the field experiment.

\begin{tabular}{|c|c|c|c|c|}
\hline Trade name & Common name & Supplier company & Method of application & Application rate \\
\hline Cruiser 350 FS & Thiamethoxam 35\% FS & $\begin{array}{c}\text { Syngenta Agro-service AG, } \\
\text { Basle/Switzerland }\end{array}$ & Seed dressing & $\begin{array}{c}0.112 \mathrm{ml} \text { per plot } \\
(350 \mathrm{ml} \text { per } 100 \mathrm{~kg})\end{array}$ \\
\hline Apron Star 42 WS & $\begin{array}{c}\text { Thiamethoxam }+ \\
\text { Difenoconazole }+ \text { Metalaxyl }\end{array}$ & $\begin{array}{c}\text { Syngenta Agro-service AG, } \\
\text { Basle/Switzerland }\end{array}$ & Seed dressing & $\begin{array}{c}0.08 \text { gram per plot } \\
\text { (225 gram per } 100 \mathrm{~kg} \text { ) }\end{array}$ \\
\hline Sevin (85\%) WP & Carbaryl & $\begin{array}{l}\text { Bayer Crop science GmbH } \\
\text { Industries, Hoechst, Germany }\end{array}$ & Foliar spraying & $\begin{array}{l}0.003 \text { kg per plot } \\
\text { (1.5 kg per hectare) }\end{array}$ \\
\hline Endosulfan 35\% EC & Endosulfan & $\begin{array}{l}\text { Adamitulu Pesticide Share } \\
\text { Company Ethiopia }\end{array}$ & Foliar spraying & $\begin{array}{c}0.004 \text { liter per plot } \\
\text { (2 to } 2.5 \text { liter per hectare) }\end{array}$ \\
\hline
\end{tabular}

